\title{
Perinatal Arterial Ischemic Stroke in Fetal Vascular Malperfusion: A Case Series and Literature Review
}

(D) A.F. Geraldo, (D) A. Parodi, (D) M. Bertamino, (D). Buffelli, (D). Uccella, (DD. Tortora, (DP. Moretti, (D) Ramenghi, (D)E. Fulcheri, (D) A. Rossi, and (D). Severino

\begin{abstract}
SUMMARY: Fetal vascular malperfusion includes a continuum of placental histologic abnormalities increasingly associated with perinatal brain injury, namely arterial ischemic stroke. Here, we describe the clinical-neuroimaging features of 5 neonates with arterial ischemic stroke and histologically proved fetal vascular malperfusion. All infarcts involved the anterior territories and were multiple in 2 patients. In 2 neonates, there were additional signs of marked dural sinus congestion, thrombosis, or both. A mixed pattern of chronic hypoxic-ischemic encephalopathy and acute infarcts was noted in 1 patient at birth. Systemic cardiac or thrombotic complications were present in 2 patients. These peculiar clinical-radiologic patterns may suggest fetal vascular malperfusion and should raise the suspicion of this rare, underdiagnosed condition carrying important implications in patient management, medicolegal actions, and future pregnancy counseling.
\end{abstract}

ABBREVIATIONS: FVM = fetal vascular malperfusion; PAIS = perinatal arterial ischemic stroke

$\mathbf{P}$ erinatal stroke is a group of cerebrovascular diseases occurring between 20 weeks of fetal life and 28 postnatal days caused by focal disruption of normal (arterial or venous) cerebral blood flow. ${ }^{1,2}$ Many patients are diagnosed several months after birth and therefore classified as having "presumed" perinatal stroke. ${ }^{1,2}$

Perinatal arterial ischemic stroke (PAIS) and presumed PAIS are the most frequent subtypes of perinatal stroke, ${ }^{2,3}$ with an overall incidence up to 1 per 1600 live births. ${ }^{4}$ They represent an important cause of cerebral palsy and are frequently associated with epilepsy and abnormal cognitive, neurosensory, and behavioral outcomes. ${ }^{2,5}$ The pathomechanisms of PAIS and presumed PAIS are very likely similar but remain elusive, with multiple maternal, fetal, and placental risk factors proposed. ${ }^{2,6}$ Of these, placental abnormalities are the least investigated. ${ }^{6}$ Indeed, scant data about the placenta have been presented in the largest multicenter PAIS studies published so far. ${ }^{7}$

Received May 7, 2020; accepted after revision July 17.

From the Units of Neuroradiology (A.F.G., D.T., A.R., M.S.), Neonatal Intensive Care (A.P., L.R.), Physical Medicine and Rehabilitation (M.B., P.M.), Gynaecologic and Fetal-Perinatal Pathology (F.B., E.F.), and Child Neuropsychiatry (S.U.), IRCCS Istituto Giannina Gaslini, Genoa, Italy; Diagnostic Neuroradiology Unit (A.F.G.), Imaging Department, Centro Hospitalar Vila Nova de Gaia/Espinho, Portugal; and Departments of Neurosciences, Rehabilitation, Ophthalmology, Genetics, Maternal and Child Health (DINOGMI) (L.R.), Surgical Sciences and Integrated Diagnostics, Pathology Division of Anatomic Pathology (E.F.), and Health Sciences (DISSAL) (A.R.), University of Genoa, Genoa, Italy.; and

This work was supported by funds of Compagnia San Paolo (Reaserch Grant to MDR; SIME 2017-0621, ROL 20573), the "Associazione per la Lotta all'IctusCerebrale" (ALICe) and "Ricerca Corrente 2020 (linea 5)" of the Italian Ministry of Health, assigned to Rehabilitation Unit of IRCCS Giannina Gaslini. These sponsors had no involvement in any of the study steps: design, data collection, analysis, and interpretation, writing of the report, and following submission.
Fetal vascular malperfusion (FVM), previously known as fetal thrombotic vasculopathy, ${ }^{8}$ is an umbrella term introduced in 2015 by the Amsterdam International Consensus group of pathologists, encompassing a spectrum of histologic placental abnormalities, frequently at different stages compatible with reduced or absent perfusion in any location of the fetoplacental vasculature, such as occlusive thrombi, mainly in large-stem vessels, accompanied by downstream changes, including organization, septation, red cell extravasation, endothelial destruction, loss of vascularity (avascular villi), and ultimately fibrosis. ${ }^{9}$ According to the location or extension of placental abnormalities, it can be further classified into low- or high-grade FVM. ${ }^{9}$ The exact pathogenesis of FVM is still not clear. However, venous stasis, endothelial or vessel wall damage, and hypercoagulability are potentially involved (Virchow triad). ${ }^{9,10}$ Importantly, there is increasing evidence that FVM plays an important role in neonatal mortality, morbidity, and outcome, including brain injury. ${ }^{11-14}$ In particular, the

Ethics approval: All procedures performed in studies involving human participants were in accordance with ethical standards of the institutional and/or national research committee and with the 1964 Helsinki declaration and its later amendments or comparable ethical standards.

Informed consent was waived due to retrospective nature of the study. Please address correspondence to Marta Bertamino, MD, PhD, Physical Therapy and Rehabilitation Unit, IRCCS Istituto Giannina Gaslini, Genoa, Italy; e-mail: MartaBertamino@gaslini.org; @MBertamino

\footnotetext{
- Indicates open access to non-subscribers at www.ajnr.org

E Indicates article with supplemental on-line tables.

Indicates article with supplemental on-line photos.

http://dx.doi.org/10.3174/ajnr.A6857
}

AJNR Am J Neuroradiol 41:2377-83 Dec 2020 www.ajnr.org 


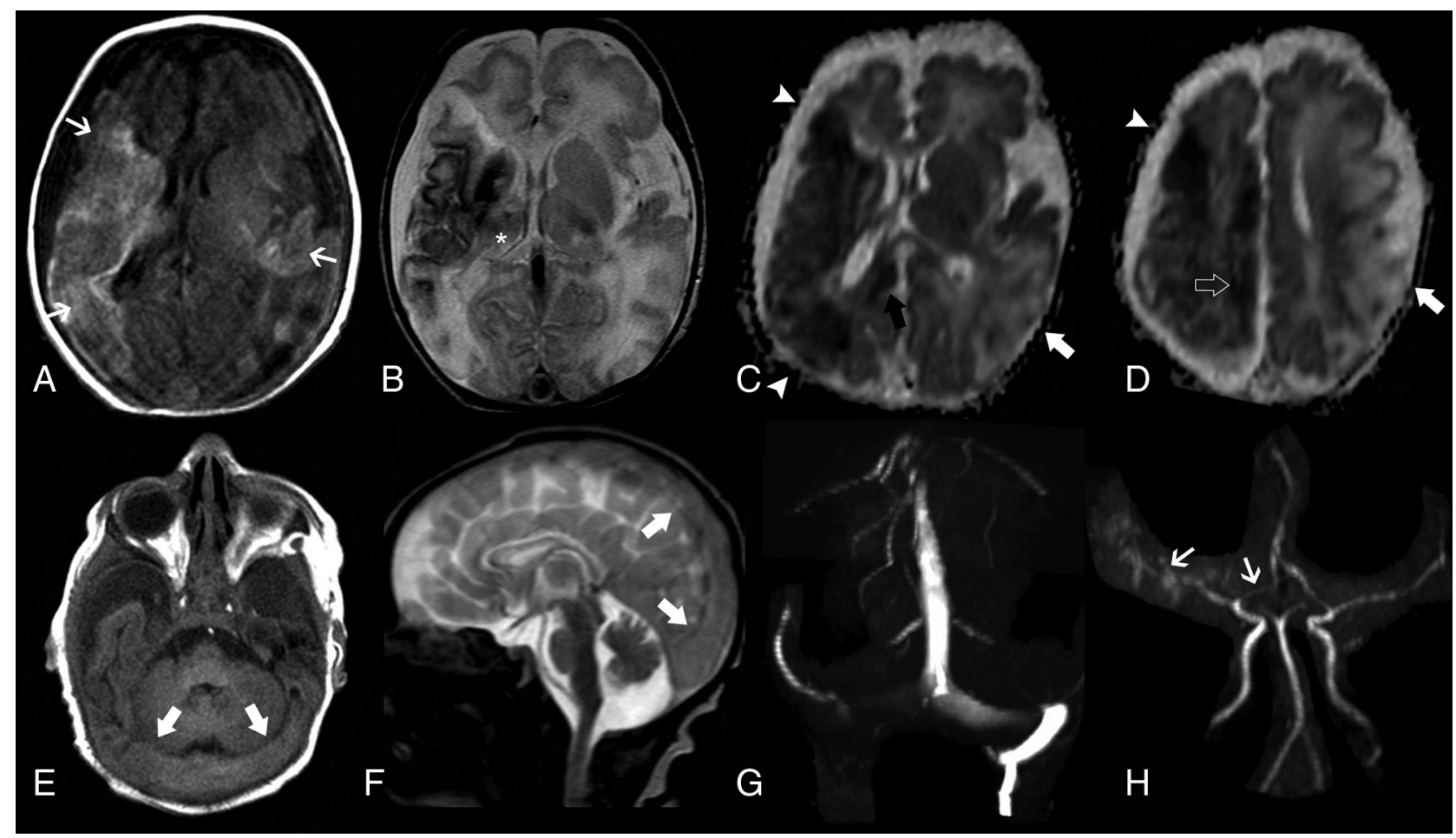

FIG 1. Brain MR imaging of patient 1 performed on day 1. Axial T1-weighted image $(A)$, T2-weighted image $(B)$, and $A D C$ maps $(C$ and $D)$ demonstrate acute ischemic infarcts in the territory of the right MCA (arrowhead) and right anterior cerebral artery (ACA) (open arrow) associated with mild diffuse atrophy of this cerebral hemisphere as well as a late subacute infarct in the territory of the left MCA (arrow). In addition, there are signs of early secondary network injury of the right thalamus (asterisk) and splenium of the corpus callosum (black arrow) as well as subcortical and deep white matter injury and laminar cortical necrosis (small arrows). Axial T1-weighted image $(E)$ and sagittal T2-weighted image $(F)$ depict marked distension of the transverse and superior sagittal sinuses (arrows) with signs of slowing of the venous blood flow, confirmed on the coronal view of $\operatorname{MRV}(G)$. MRA $(H)$ shows reduced visualization of the right MCA and ACA branches compared with the contralateral side (small arrows).

association between FVM and perinatal arterial and venous stroke is increasingly acknowledged..$^{10,11,13-17}$ On the other hand, FVM remains an underrecognized cause of PAIS because the onset of clinical manifestations is usually around 12-72 hours after birth or even months later in presumed PAIS, thus limiting the availability of placental tissue for histologic examination. ${ }^{2,18,19}$ Moreover, reports focusing on imaging data of patients with PAIS in the context of proved FVM are still limited, especially within the radiology literature. ${ }^{11,13,15-18}$ Nevertheless, failure to recognize this etiology may have important implications in patient management, as well as in medicolegal actions and future pregnancy counseling. ${ }^{19}$ Therefore, it is crucial to increase awareness of FVM-related PAIS in the neuroradiology community and to highlight the importance of knowing the results of placenta examination when reporting these cases.

Here, we describe the neuroradiological features of 5 neonates with PAIS and histologically proved FVM and their correlation with histopathologic and clinical findings as well as neurologic outcome.

\section{CASE SERIES}

Regional review board approval was obtained for this single-center series (N.096/2019), waiving parental written informed consent. Five patients with PAIS and histologically proved FVM were identified from the institutional database of pediatric patients treated for stroke at the Gaslini Children's Hospital between 2012 and 2019. All patients were initially investigated by cranial sonography followed by brain MR imaging in 4 patients (range: 1 day- 2.3 months). Longitudinal brain MR imaging were obtained in 3 neonates (range: 14 days-2.4 years). In total, 11 brain MR imaging and 2 head CT studies were available for review. Images were analyzed in consensus by 2 pediatric neuroradiologists (M.S. and A.F.G., 10 and 5 years' experience, respectively). FVM histologic features were reviewed by 2 pathologists (E.F. and F.B., 30 and 5 years' experience, respectively) and classified into high or low grade. ${ }^{9}$ Clinical data at diagnosis and follow-up (range: 15 days-5 years) were obtained from electronic charts.

On-line Table 1 lists clinical and placental features and the outcomes of our cohort. Neuroimaging features are summarized in On-line Table 2. Parents were nonconsanguineous, and family history was unremarkable in all patients. All neonates were male and born by cesarean section (4/5 urgent procedures). Two neonates were born from dichorionic diamniotic twin pregnancies. Three pregnancies were complicated by threatened preterm labor, preterm premature rupture of membranes, and preeclampsia. Mean gestational age at birth was 34.2 weeks (range: 30-39 weeks). Intrauterine growth restriction was diagnosed in 3/5 patients. Mean birth weight was $1843 \mathrm{~g}$ (range: 910-3280 g), length was $42 \mathrm{~cm}$ (range: $35-51 \mathrm{~cm}$ ), and head circumference was $30 \mathrm{~cm}$ (range: 26$34 \mathrm{~cm}$ ). PAIS was symptomatic at birth in $3 / 5$ neonates (clonic seizures and apneas) and was incidentally discovered in 2/5 neonates. In all patients, coagulopathies and congenital cardiac malformations were not detected. Associated clinical findings included a large 


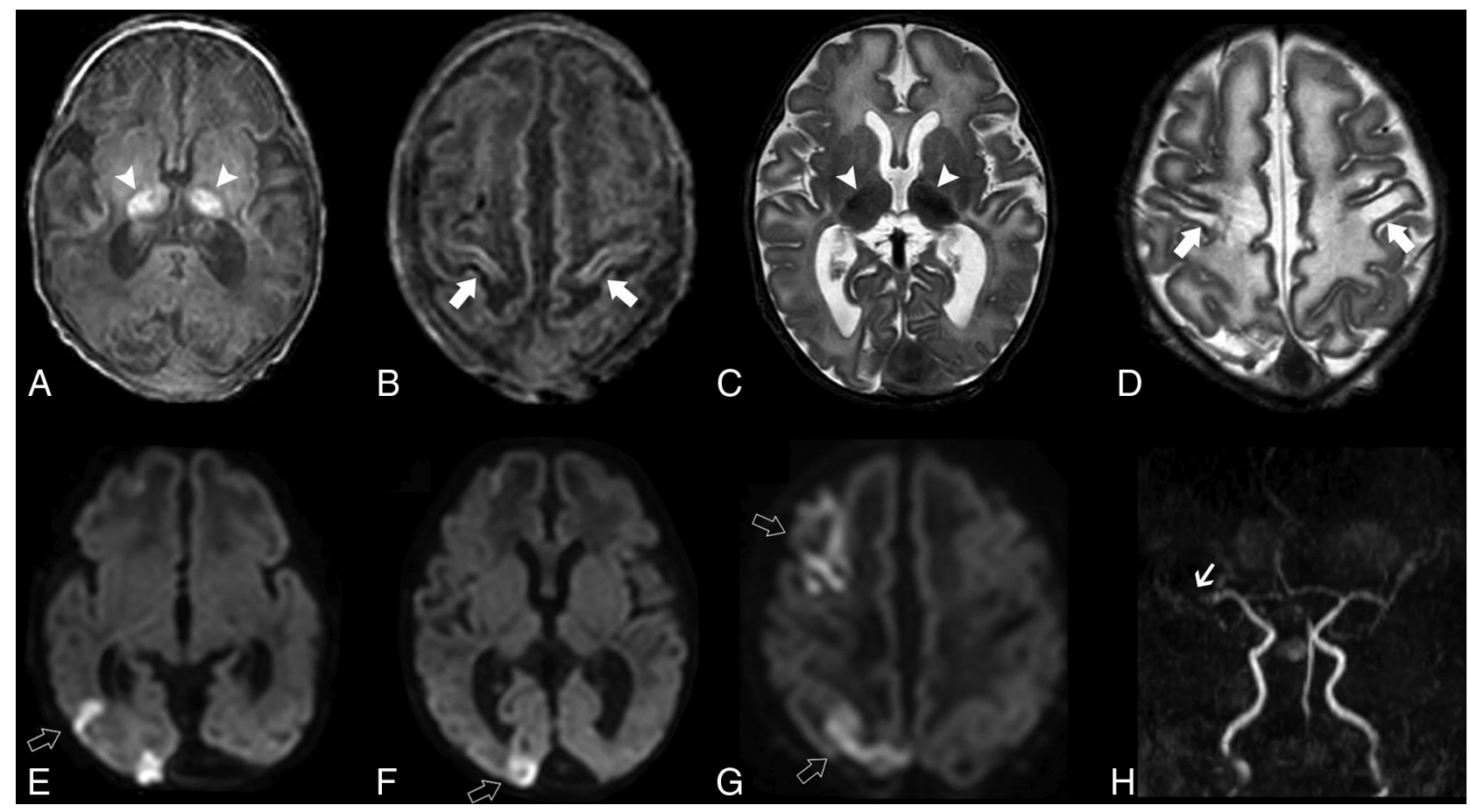

FIG 2. Brain MR imaging of patient 2 performed on day 1. Axial T1-weighted image $(A$ and $B)$, T2-weighted $(C$ and $D)$ and diffusion-weighted $(E-G)$ images show bilateral atrophy and abnormal T1 and T2 signal intensity of the thalami (arrowheads) and perirolandic regions (arrows) in the context of hypoxic-ischemic lesions. Also note multiple areas of acute ischemic infarct distributed in the right MCA territory and watershed region (open arrows). MRA $(H)$ demonstrates reduced flow-related signal of the right MCA branches (small arrow).

deep skin ulcer related to distal thromboembolism $(n=1$, On-line Fig 1), transient myocardial ischemia $(n=1)$, respiratory distress syndrome of prematurity $(n=3)$, and necrotizing enterocolitis $(n=1)$.

Cranial sonography findings were abnormal in $4 / 5$ patients, showing unilateral or bilateral WM hyperechogenicity $(n=3)$ and a focal irregular cavitation in the parietal subcortical WM ( $n=1$, On-line Fig 2).

On imaging, PAISs were multiple in 2/5 patients and involved the anterior circulation in all patients (MCA in 4 neonates, with additional anterior cerebral artery involvement in 1 patient), mostly with a superficial involvement (4/5 patients, On-line Fig 3). In 2/5 patients, PAIS was detected in different phases (acute, subacute, or chronic) at birth (Figs 1 and 2). Signs of early corticobasal diaschisis were noted in 3/4 patients, and early Wallerian degeneration of the corticospinal tract was present in $2 / 4$ patients (Fig 3). Concomitant dural sinus congestion, thrombosis, or both was depicted in 2/5 patients, 1 of whom also displayed signs of chronic hypoxic-ischemic encephalopathy at birth (Figs 1, 2 and On-line Fig 4). MRA at diagnosis was available in 2 patients, showing reduced flow-signal in the involved arteries. Follow-up brain MR imaging and MRA studies demonstrated chronic evolutions of PAIS, without new arterial infarcts, in $2 / 3$ patients. In 1 patient, we observed the phenomenon of DWI reversal of the cortical ischemic lesions, in keeping with spontaneous blood flow restoration in the affected distal MCA branches. ${ }^{20}$ Resolution of dural sinus congestion and thrombosis was noted in $2 / 2$ patients (On-line Figs 4 and 5).
Histologic examination of the placenta revealed long-standing high-grade FVM in different evolutionary stages in all affected patients (Fig 4). In both dichorionic diamniotic twin pregnancies, FVM was detected in the chorionic disk of each twin with brain injury, but no signs of FVM were found in the chorionic disk of the unaffected co-twin. The placentas of the co-twins presented minor signs of long-standing hypoxic damage and asynchronous patchy ischemic lesions in 1 patient and focal congestion with recent intravillous hemorrhages in the other. Signs of maternal vascular malperfusion were present in $4 / 5$ patients. Umbilical cord abnormalities were present in all affected patients: nuchal cord $(n=2)$, hypercoiled $(n=1)$, hypocoiled $(n=1)$, and false knots with torsion $(n=1)$. No signs of inflammation of the umbilical cord, membranes, or amniochorial vessels were depicted in any of the patients.

The preterm neonate who developed necrotizing enterocolitis died at 15 days of life. Mean age at last clinical follow-up of the remaining patients was 28 months (range: 6-60). Moderate to severe developmental delay was diagnosed in 3 children, associated with microcephaly in 2 patients. Motor deficits were present in 3/5 children; 1 developed drug-resistant epilepsy, required noninvasive respiratory support and enteral artificial nutrition through gastrostomy at 9 months of age, and died at 10 months after a respiratory infection. Both co-twins of the 2 affected patients were born with appropriate birth weight, length, and head circumference for gestational age and presented with normal psychomotor development at last follow-up (24 and 36 months, respectively). 


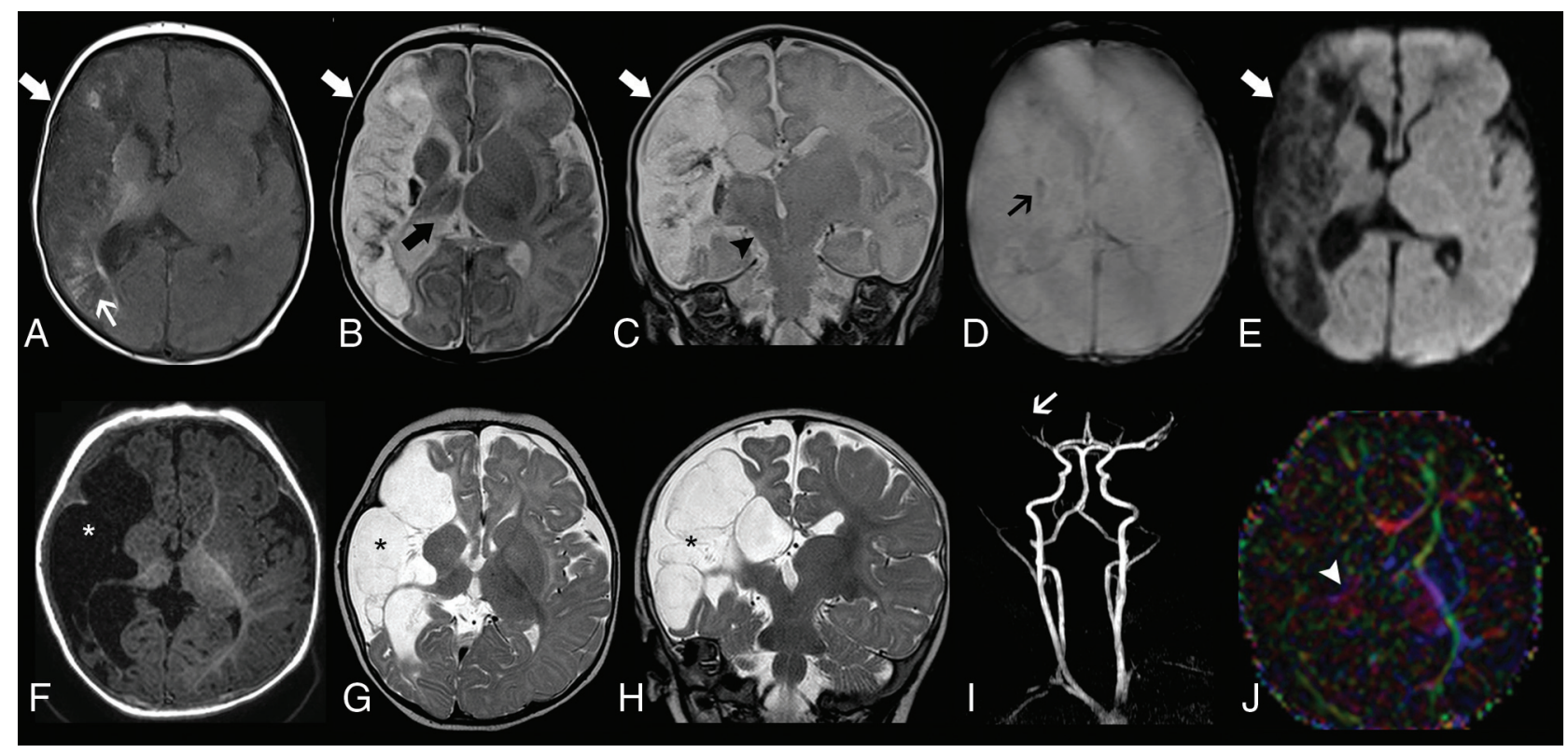

FIG 3. Longitudinal neuroimaging evaluation of patient 5 . Initial brain MR imaging obtained at 18 days of life, including axial 7 -weighted image $(A)$, axial $(B)$ and coronal $(C)$ T2-weighted images, axial T2* image $(D)$ and diffusion-weighted image $(E)$, demonstrate a large ischemic infarct in the superficial and deep territory of the right MCA in the late subacute or early chronic phase (arrows). There are associated areas of cortical laminar necrosis (thin white arrow) and a focus of hemorrhagic transformation (thin black arrow). Also note signs of ipsilateral thalamic diaschisis (thick black arrow) and Wallerian degeneration of the corticospinal tract (arrowhead). Follow-up brain MR imaging performed at 6 months $(F-)$ ). Axial T-weighted image $(A)$ and axial (B) and coronal (C) T2-weighted images depict progressive cystic encephalomalacia and atrophy in the infarcted area with ex vacuo enlargement of the adjacent CSF spaces (asterisks). MRA reveals reduced visibility of right MCA branches (arrow). Axial directionally encoded color fractional anisotropy (FA) map at the level of the basal ganglia shows markedly reduced FA of the posterior limb of the right internal capsule (arrowhead).

\section{DISCUSSION}

Data on neuroimaging features of neonatal stroke associated with thrombotic or inflammatory placental disorders are very rare. ${ }^{15,17}$ In the largest study, which was by Bernson-Leung et al, ${ }^{17}$ collecting 46 children with neonatal arterial or venous ischemic stroke from 3 academic medical centers, 13/28 (46.4\%) PAISs and 10/18 (55.5\%) venous strokes were linked to FVM. Regarding the imaging pattern, PAIS mostly involved the left hemisphere in the MCA territory and was frequently multiple or superficial, but the right hemisphere or perforator territories were affected only in a minority of patients. ${ }^{15,17}$ Similarly, we found that the anterior territories were always involved with sparing of the posterior circulation. In addition, multiple recurrent infarcts and/or small corticosubcortical infarcts were prevalent, suggesting a thromboembolic phenomenon occurring at different phases as the most plausible pathomechanism linking FVM to PAIS. Indeed, because the rate of thrombophilia is similar in placentas with and without FVM, ${ }^{12,13}$ the main hypothesis is the spread of FVM-related thromboemboli into the venous fetal circulation, in turn reaching the aorta and then the intracranial vessels through a patent foramen ovale and a right-to-left direction of blood flow in the fetal ductus arteriosus. ${ }^{21,22}$ Predominant involvement of the MCA territory is also described in most studies including patients with PAIS of mixed or unknown cause, ${ }^{3,7,23}$ though multiple infarcts are usually less frequent $(<20 \%-30 \%){ }^{23}$ Interestingly, some of the recurrent infarcts seen in our cohort appeared to be chronic with cortical T1 hyperintensity indicative of laminar necrosis despite having been detected in neonates on day 1 ; such observation favors an intrauterine onset, as expected to occur in FVM.
Reduced flow signal involving distal arterial branches ipsilateral to the ischemic strokes was present in 2 patients in this series. Intracranial arterial abnormalities have been reported in a subset of neonates with PAIS of variable causes, ${ }^{24-26}$ likely reflecting reduced arterial blood supply to the infarcted territory and/or persistently occluded or near-occluded vessels in the context of a proximal thromboembolism. ${ }^{24,25}$ We did not identify large-vessel occlusions in any of our patients, but these have only been exceptionally described in FVM-related PAIS, ${ }^{19,21}$ probably caused by rapid vessel recanalization in neonates and/or more distal embolization. ${ }^{19,27}$

Interestingly, 2 of our neonates presented additional features related to severe venous congestion and/or thrombosis involving the superior sagittal and transverse sinuses. The co-occurrence of both arterial and venous complications in the setting of FVM has not been reported before but is theoretically plausible because FVM has been described in association with both PAIS and isolated neonatal cerebral sinovenous thrombosis. ${ }^{5,17}$ In particular, this peculiar combination might be caused by common risk factors underlying FVM, activating coagulation and inflammatory pathways in both the arterial and venous system ${ }^{28}$ or by secondary marked reduction of venous flow in the dural sinuses caused by diffuse fetoplacental venous stasis. ${ }^{17}$ On the other hand, additional risk factors previously described in the literature for neonatal dural sinovenous thrombosis ${ }^{29,30}$ and not necessarily related to FVM, such as emergent cesarean section, might have contributed to venous complications in the present patients. Therefore, future studies on larger series are needed to elucidate the role of FVM in perinatal venous stroke and to estimate the exact prevalence of both arterial and venous abnormalities in neonates with documented FVM. 

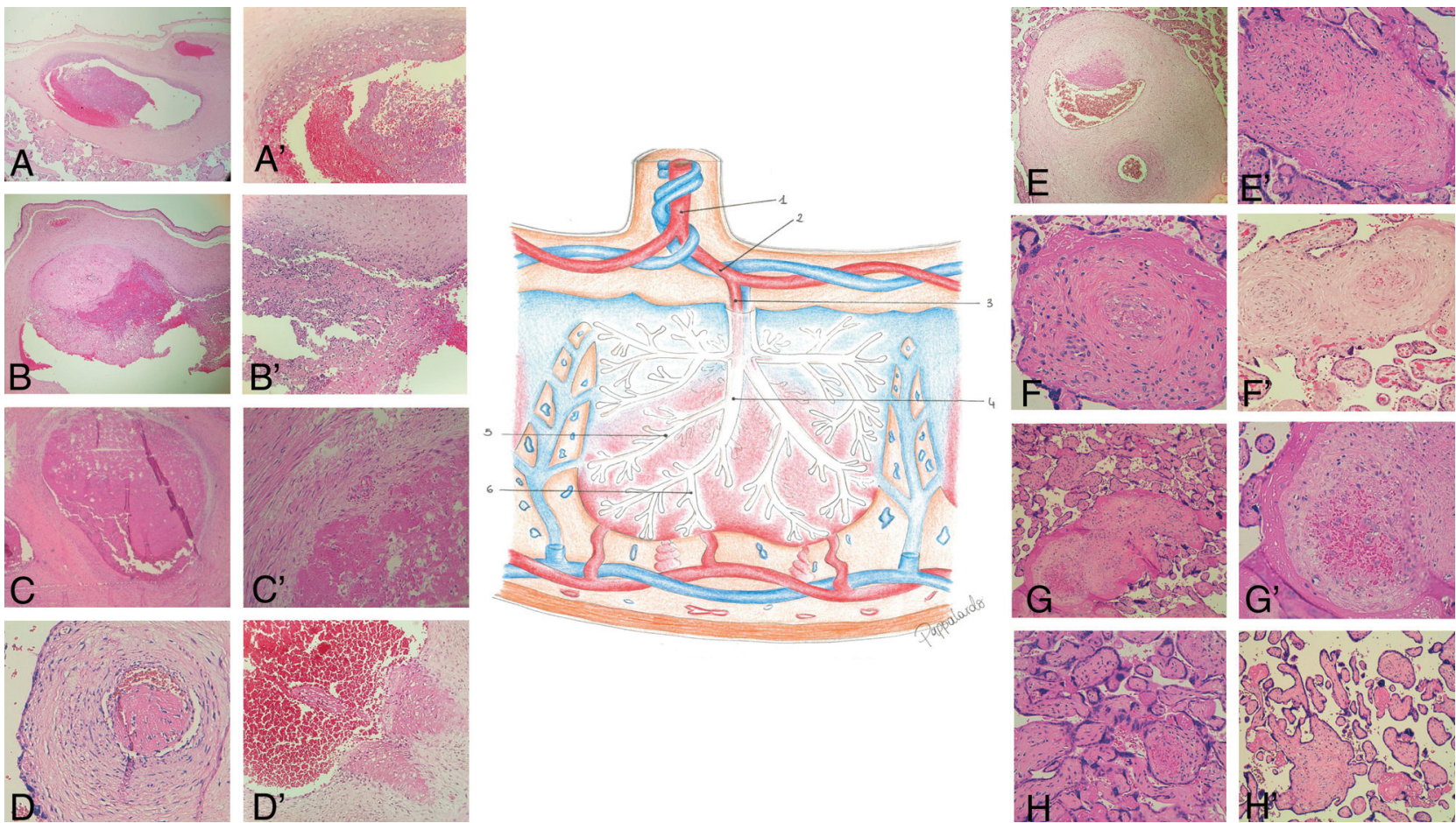

FIG 4. Schematic representation of the placental fetal vascularization and histologic features of fetal vascular malperfusion. 1 . Vessel of umbilical cord. 2. Amniochorial vessels $\left(A, A^{\prime}, B, B^{\prime}\right)$. 3. First-order stem vessels $\left(C, C^{\prime}\right)$. 4. Second-order stem vessels $\left(D, D^{\prime}\right)$. 5. Third-order stem vessels $\left(E, E^{\prime}, F\right)$. 6. Fourth-order stem vessels $\left(F^{\prime}, G, G^{\prime}, H\right)$. A. Amniochorial vessel with dilated lumen occupied by a floating thrombus adhering to the wall by means of coagulation (patient 5). $A^{\prime}$. Detail of the previous figure: evidence of wall damage in the form of a necrotic fibrinoid band (patient 5). B. Amniochorial vessel with dilated lumen in which a thrombus in various phases of evolution adheres to the wall; the thrombus has a fibrous nucleus, at the margins of which a recent coagulation and a fibrous thrombus in a medium stage of evolution are observed (patient 5). $B^{\prime}$. Detail of $B$ : granulocytic infiltrate of the wall indicating vasculitis as the cause of thrombosis (patient 5). $C$. First-order stem vessel totally occupied by a long-standing thrombus adherent to the wall (patient 1). $C^{\prime}$. Detail of $C$, a segment of the destructured wall shows evolving lesions after adhesion of the thrombus (patient 1). D. Second-order stem vessel with a thrombotic formation occluding the lumen without adhering to the wall (patient 3). $D^{\prime}$. Second-order stem vessel with wall lesion and initial detachment of a floating thrombus into the bloodstream. E. Thirdorder stem vessel displaying wall damage and initial adhesion of a fibrinoid thrombus. $E^{\prime}$. Third-order stem vessel with the lumen completely occluded by a long-standing thrombotic formation hampering the recognition of vessel wall structure (patient 1). F. Third-order stem vessel with a long-standing partly recanalized occlusive thrombus (patient 1). $F^{\prime}$. Fourth-order stem vessel: occluded lumen with revascularization; adjacent to this, a totally occluded vessel whose wall structure is no longer recognizable (patient 4). G. Fourth-order stem vessel displaying initial recanalization and endothelial proliferation promoting endoluminal neoangiogenesis (patient 1). $G^{\prime}$. Detail of $G$ showing the intermixing of nonagglutinated erythrocytes and incomplete neo-formed vessels (patient 1). $\mathrm{H}$. Fourth-order stem vessel: the lumen is occupied by a long-standing thrombotic formation but displays recanalization; villi undergoing ischemic necrosis caused by perfusion block (patient 1). $H^{\prime}$. Group of villi undergoing ischemic necrosis; long-standing lesion integrates the picture of so-called avascularized villi (patient 3).

Another peculiar finding in our series was the concurrence of clinical and imaging signs of chronic hypoxic-ischemic encephalopathy and multiple acute infarcts in 1 neonate at birth. Although it is accepted that FVM is a risk factor for both hypoxic-ischemic encephalopathy and PAIS ${ }^{31,32}$ and both neonatal hypoxic-ischemic encephalopathy and PAIS involve hypoxia-ischemia, patients with a mixed pattern on neuroimaging have not been described in the setting of proven FVM to the best of our knowledge. Such combination, although rare, may be a potential alerting sign of FVM in neonates with PAIS. In addition, as documented in our series and previously described in the literature, the presence of intrauterine growth retardation, thromboembolism in multiple organs, or cardiac complications in neonates with PAIS are also associated with FVM and should raise suspicion of this underestimated condition. ${ }^{12,19,33}$

Previous studies reported an extremely low rate of recurrence of stroke after PAIS even in the context of $\mathrm{FVM},{ }^{10}$ supporting the concept that risk factors associated with both FVM and PAIS completely subside outside the perinatal period in most patients. Similarly, we did not detect additional infarcts on follow-up studies nor the appearance of clinical manifestations related to new arterial ischemic strokes. Independent of the subjacent etiology, PAIS frequently results in epilepsy, cerebral palsy, and cognitive deficits. ${ }^{2,5}$ In our cohort, 1 preterm neonate died during the neonatal period because of severe necrotizing colitis. Adverse neurologic outcomes were detected in most of the other patients, representing a higher proportion than that described in most series of PAIS. ${ }^{22}$ However, these data should be considered with caution because they might be related to selection bias caused by nonsystematic evaluation of placenta histology.

High-grade FVM is associated with a higher risk of brain injury. ${ }^{16}$ Indeed, all our patients were classified as having highgrade FVM, showing occlusive thrombi, mainly in large-stem vessels, accompanied by downstream changes, including organization, 
septation, red cell extravasation, endothelial destruction, loss of vascularity and, ultimately, fibrosis. These changes are similar to those seen in intrauterine fetal demise but are focal rather than diffuse and, especially, in different stages of evolution. ${ }^{9}$ However, no differences in terms of severity and extension of FVM-related lesions were noted among patients with severe or mild imaging patterns in our series. This is in agreement with prior literature showing no stringent correlation between MR imaging and histologic data. ${ }^{10}$

Although the likelihood of FVM and PAIS is thought to be increased by endothelial damage caused by fetal inflammatory response, ${ }^{9}$ these lesions were not detected in the present series. On the other hand, as documented in almost all our patients, FVM is frequently associated with other placental abnormalities, such as maternal vascular malperfusion. ${ }^{10,34}$ Interestingly, we had 2 cases of twin dichorionic diamniotic pregnancies, but no co-twin had a stroke or evidence of FVM features in the corresponding placenta, as previously demonstrated. ${ }^{17}$ Of note, umbilical cord abnormalities (ie, potentially obstructing anatomic lesions and/or clinical conditions) are considered major risk factors of FVM, probably through promotion of venous obstruction, congestion, and stasis. ${ }^{10,11}$ Accordingly, 4 neonates presented cord abnormalities associated with FVM, including entanglements, hypercoiling, and/or torsion. Unfortunately, placentas are generally discarded soon after delivery, but the clinical presentation of PAIS is often mild and nonspecific, and the diagnosis is most often made a few days or even months after birth, as in the present series. ${ }^{2,6}$ These are major limitations in the diagnosis of FVM in PAIS, and the extent to which different FVM histologic patterns and umbilical cord anomalies may impact on the type of PAIS or brain injury at birth remains an intriguing issue awaiting further exploration.

In conclusion, we confirm the prevalent involvement of the anterior circulation in FVM-related PAISs that were frequently multiple, asynchronous, and distributed superficially, thus suggesting an embolic origin. Moreover, we describe for the first time the cooccurrence of imaging signs of hypoxic-ischemic lesions and/or dural sinus congestion or thrombosis in these neonates, and the association of these features with FVM is worth further investigation. Together with clinical manifestations such as intrauterine growth retardation, thromboembolism in other organs, and cardiac complications, these MR imaging features may raise the suspicion of a subjacent FVM, a rare but likely underdiagnosed condition. Larger prospective studies including placental examination in all neonates are needed to clarify the pathomechanisms of FVM-related PAIS and the correlation between clinical, imaging, and histologic findings.

\section{ACKNOWLEDGMENTS}

We are grateful to the associations Associazione per la Lotta all'Ictus Cerebrale (ALICe) and FightTheStroke for their support of our study. We also thank Doctor Simona Pappalardo for the drawing of Fig 4.

Disclosures: Ana Geraldo_UNRELATED: Grants/Grants Pending: ESNR, Comments: Annual Research Fellowship in diagnostic neuroradiology, paid to individual. Alessandro Parodi-RELATED: Grant: Compagnia di San Paolo (ROL 20573), Associazione per la Lotta all'IctusCerebrale (ALICe) and Ricerca Corrente Disordini Neurologici e Muscolari (Linea 5) of Italian Ministry of Health*; UNRELATED:
Consultancy: Shire HGT, Comments: Consultancy for assessment of cranial ultrasound examinations from ROPP-2008-01 Study. Marta Bertamino-RELATED: Grant: Compagnia di San Paolo (ROL 20573), ALICe and Ricerca Corrente Disordini Neurologici e Muscolari (Linea 5) of Italian Ministry of Health*. Compagnia di San Paolo (ROL 20573), the ALICe and Ricerca Corrente Disordini Neurologici e Muscolari (Linea 5) of Italian Ministry of Health*. Sara Uccella—RELATED: Grant: Compagnia di San Paolo (ROL 20573), ALICe and Ricerca Corrente Disordini Neurologici e Muscolari (Linea 5) of Italian Ministry of Health*. Paolo Moretti-RELATED: Grant: Compagnia San Paolo (ROL 20573); the ALIC) and Ricerca Corrente Disordini Neurologici e Muscolari (Linea 5) of Italian Ministry of Health*. Mariasavina Severino-RELATED: Grant: Compagnia di San Paolo (ROL 20573), ALICe and Ricerca Corrente Disordini Neurologici e Muscolari (Linea 5) of Italian Ministry of Health, Comments: These sponsors had no involvement in any of the study steps: design, data collection, analysis, and interpretation, writing of the report, and following submission*; UNRELATED: Employment: Neuroradiology consultant, IRCCS Istituto Giannina Gaslini. Luca Ramenghi-RELATED: Grant: Compagnia di San Paolo (ROL 20573), ALICe and Ricerca Corrente Disordini Neurologici e Muscolari (Linea 5) of Italian Ministry of Health*; UNRELATED: Employment: IRCCS Gaslini, Department of Neurosciences, Rehabilitation, Ophthalmology, Genetics, and Maternal and Children's Sciences, University of Genoa, Genoa, Italy, Comments: Chief of Mother-Baby Department. *Money paid to the institution.

\section{REFERENCES}

1. Raju TNK, Nelson KB, Ferriero D, et al. Ischemic perinatal stroke: summary of a workshop sponsored by the National Institute of Child Health and Human Development and the National Institute of Neurological Disorders and Stroke. Pediatrics 2007;120:609-16 CrossRef Medline

2. Dunbar M, Kirton A. Perinatal stroke: mechanisms, management, and outcomes of early cerebrovascular brain injury. Lancet Child Adolesc Health 2018;2:666-76 CrossRef Medline

3. Wagenaar N, Martinez-Biarge M, van der Aa NE, et al. Neurodevelopment after perinatal arterial ischemic stroke. Pediatrics 2018;142:e20174164 CrossRef Medline

4. Laugesaar R, Kolk A, Tomberg T, et al. Acutely and retrospectively diagnosed perinatal stroke: a population-based study. Stroke 2007;38:223440 CrossRef Medline

5. Kirton A, deVeber G. Life after perinatal stroke. Stroke 2013;44:326571 CrossRef Medline

6. Mineyko A, Kirton A. The black box of perinatal ischemic stroke pathogenesis. J Child Neurol 2011;26:1154-62 CrossRef Medline

7. Kirton A, Armstrong-Wells J, Chang T, et al. Symptomatic neonatal arterial ischemic stroke: the International Pediatric Stroke Study. Pediatrics 2011;128:e1402-10 CrossRef Medline

8. Redline RW, Pappin A. Fetal thrombotic vasculopathy: the clinical significance of extensive avascular villi. Hum Pathol 1995;26:80-85 CrossRef Medline

9. Khong TY, Mooney EE, Ariel I, et al. Sampling and definitions of placental lesions: Amsterdam Placental Workshop Group Consensus Statement. Arch Pathol Lab Med 2016;140:698-713 CrossRef Medline

10. Redline RW, Ravishankar S. Fetal vascular malperfusion, an update. APMIS 2018;126:561-69 CrossRef Medline

11. Redline RW. Severe fetal placental vascular lesions in term infants with neurologic impairment. Am J Obstet Gynecol 2005;192:452-57 CrossRef Medline

12. Saleemuddin A, Tantbirojn $P$, Sirois $K$, et al. Obstetric and perinatal complications in placentas with fetal thrombotic vasculopathy. Pediatr Dev Pathol 2010;13:459-64 CrossRef Medline

13. Roescher AM, Timmer A, Erwich JJHM, et al. Placental pathology, perinatal death, neonatal outcome, and neurological development: a systematic review. PLoS One 2014;9:e89419 CrossRef Medline

14. Kraus FT, Acheen VI. Fetal thrombotic vasculopathy in the placenta: cerebral thrombi and infarcts, coagulopathies, and cerebral palsy. Hum Pathol 1999;30:759-69 CrossRef Medline

15. Elbers J, Viero S, MacGregor D, et al. Placental pathology in neonatal stroke. Pediatrics 2011;127:e722-29 CrossRef Medline

16. Chisholm KM, Heerema-McKenney A. Fetal thrombotic vasculopathy. Am J Surg Pathol 2015;39:274-80 CrossRef Medline 
17. Bernson-Leung ME, Boyd TK, Meserve EE, et al. Placental pathology in neonatal stroke: a retrospective case-control study. J Pediatr 2018;195:39-47.e5 CrossRef Medline

18. Fluss J, Garcia-Tarodo S, Granier M, et al. Perinatal arterial ischemic stroke related to carotid artery occlusion. Eur J Paediatr Neurol 2016;20:639-48 CrossRef Medline

19. Heider A. Fetal vascular malperfusion. Arch Pathol Lab Med 2017;141:1484-89 CrossRef Medline

20. Nagaraja N, Forder JR, Warach S, et al. Reversible diffusionweighted imaging lesions in acute ischemic stroke: a systematic review. Neurology 2020;94:571-87 CrossRef Medline

21. Cheong JLY, Cowan FM. Neonatal arterial ischaemic stroke: obstetric issues. Semin Fetal Neonatal Med 2009;14:267-71 CrossRef Medline

22. Chabrier S, Saliba E, Nguyen The Tich S, et al. Obstetrical and neonatal characteristics vary with birthweight in a cohort of 100 term newborns with symptomatic arterial ischemic stroke. Eur J Paediatr Neurol 2010;14:206-13 CrossRef Medline

23. Husson B, Hertz-Pannier L, Renaud C, et al. Motor outcomes after neonatal arterial ischemic stroke related to early MRI data in a prospective study. Pediatrics 2010;126:e912 CrossRef Medline

24. Husson B, Hertz-Pannier L, Adamsbaum C, et al. MR angiography findings in infants with neonatal arterial ischemic stroke in the middle cerebral artery territory: a prospective study using circle of Willis MR angiography. Eur J Radiol 2016;85:1329-35 CrossRef Medline

25. Siddiq I, Armstrong D, Surmava A-M, et al. Utility of neurovascular imaging in acute neonatal arterial ischemic stroke. $J$ Pediatr 2017;188:110-14 CrossRef
26. Wintermark M, Hills NK, DeVeber GA, et al. Clinical and imaging characteristics of arteriopathy subtypes in children with arterial ischemic stroke: results of the VIPS study. AJNR Am J Neuroradiol 2017;38:2172-79 CrossRef Medline

27. van der Aa NE, Porsius ED, Hendrikse J, et al. Changes in carotid blood flow after unilateral perinatal arterial ischemic stroke. Pediatr Res 2012;72:50-56 CrossRef Medline

28. Prandoni P. Venous and arterial thrombosis: is there a link? $A d v$ Exp Med Biol 2017;906:273-83 CrossRef Medline

29. Rutherford MA, Ramenghi LA, Cowan FM. Neonatal stroke. Arch Dis Child Fetal Neonatal Ed 2013;98:F180 CrossRef Medline

30. Ramenghi LA, Cardiello V, Rossi A. Neonatal cerebral sinovenous thrombosis. Handb Clin Neurol 2019;162:267-80 CrossRef Medline

31. Mir IN, Johnson-Welch SF, Nelson DB, et al. Placental pathology is associated with severity of neonatal encephalopathy and adverse developmental outcomes following hypothermia. Am J Obstet Gynecol 2015;213:849.e1-7-849.e7 CrossRef Medline

32. Vik T, Redline R, Nelson KB, et al. The placenta in neonatal encephalopathy: a case-control study. J Pediatr 2018;202:77-85.e3 CrossRef Medline

33. Gluck O, Schreiber L, Marciano A, et al. Pregnancy outcome and placental pathology in small for gestational age neonates in relation to the severity of their growth restriction. J Matern Fetal Neonatal Med 2019;32:1468-73 CrossRef

34. Zur RL, Kingdom JC, Parks WT, et al. The placental basis of fetal growth restriction. Obstet Gynecol Clin North Am 2020;47:81-98 CrossRef Medline 